\title{
Historia de una excepción perfecta
}

Norma y usos del pretérito perfecto compuesto en español actual

\section{Carlos Soler Montes}

\section{(2) OpenEdition}

Journals

Edición electrónica

URL: https://journals.openedition.org/cher/829

DOI: $10.4000 /$ cher.829

ISSN: 2803-5992

Editor

Presses universitaires de Strasbourg

Edición impresa

Fecha de publicación: 12 diciembre 2019

Paginación: 45-60

ISBN: 979-10-344-0057-7

ISSN: 1968-035X

Referencia electrónica

Carlos Soler Montes, «Historia de una excepción perfecta», reCHERches [En línea], 23 | 2019, Publicado el 22 septiembre 2021, consultado el 18 noviembre 2021. URL: http://journals.openedition.org/cher/ 829 ; DOI: https://doi.org/10.4000/cher.829 


\title{
Historia de una excepción perfecta Norma y usos del pretérito perfecto compuesto en español actual
}

\author{
Carlos SOLer Montes ${ }^{1}$
}

$\mathrm{E}$ n este trabajo vamos a contar la historia de un tiempo verbal excepcional en esencia, el pretérito perfecto compuesto (en adelante, PPC) ${ }^{2}$, que desde sus orígenes se situó en un lugar gramatical y semántico complejo, muy flexible y algo difuso para los hablantes, que lo han estado utilizando desde hace siglos (literalmente) en la mayoría de lenguas románicas. Para el caso concreto del español, la tendencia a la excepción en el uso del PPC radica en entender los límites que este establece al trazar una relación de anterioridad respecto al momento del habla. Mientras que, en teoría, el pretérito perfecto simple indica un espacio temporal que se constituye en un ámbito únicamente pasado, la forma compuesta se refiere a la anterioridad dentro de la esfera del presente, y pertenece, por tanto, a la actualidad del hablante.

Para ilustrar debidamente la situación actual de este tiempo verbal tenemos que detenernos, en un primer momento, en la noción de aspecto verbal (Weinrich 1964, Comrie 1976, y en relación directa con el contexto del español: Rona 1973, Rojo 1974, Gutiérrez Araus 1997), que consiste en la representación que hace el hablante del proceso expresado por el verbo, es decir, la representación de su duración, su desarrollo o su terminación. El punto de partida para entender el PPC será, pues, el hecho de conectar un contenido de anterioridad a la indicación que realiza en el presente. Se trata de un presente anterior en términos de localización temporal, aunque encontremos en este tiempo otro

1 Carlos Soler Montes, The University of Edinburgh, ORCID: 0000-0002-4085-9878

2 El pretérito perfecto compuesto también se conoce dentro de la literatura especializada, a causa de su relación temporal directa con el presente, como antepresente, o incluso presente perfecto, en un intento más pedagógico que lingüístico de correspondencia con los tiempos verbales del inglés; o simplemente pretérito perfecto por oposición a su tiempo homólogo simple llamado tradicionalmente indefinido. En este trabajo utilizaremos la terminología adoptada por la Real Academia Española y la Asociación de Academias de la Lengua Española en su Nueva gramática: pretérito perfecto compuesto (2009: 1722). 
sentido más que expresa un estado de continuidad de los eventos, o también el reflejo de realizar dicha acción. Para Carrasco (2008: 22), el contenido de anterioridad, que se une de manera lógica al contenido de simultaneidad típico de esta forma verbal, es parte de la esencia del peculiar significado aspectual de perfecto del PPC y, quizás, parte de su ambivalencia, o de la «imperfectividad latente» de la que habla Cartagena (1999).

Esta bipolaridad, que se circunscribe en torno al límite entre el presente y el pasado dentro del PPC, convierte a este tiempo en una forma verbal muy ambigua, de difícil interpretación, una forma excepcional en la historia de nuestra lengua, pues se puede considerar como acabada, inacabada, resultado de algo o en desarrollo, en según qué casos o perspectivas.

La herencia gramatológica de pasado reciente o antepresente, tal como lo bautizó Andrés Bello en su Gramática (1847: 436), valor que coincide plenamente con la norma y la tradición de su uso en la lengua española, ha hecho que este tipo de usos se haya extendido en libros de texto y gramáticas pedagógicas tanto para nativos como para estudiantes de español, provocando, en parte, una simplificación del sistema y reduciendo la variedad aspectual de este tiempo verbal a usos ejemplares en contextos muy acotados, y propiciando así todo tipo de excepciones que no se han sabido clasificar o aceptar como lo que son, usos correctos de este tiempo verbal.

\section{Orígenes de excepción}

Si analizamos el PPC desde una perspectiva histórica, entenderemos que una de las innovaciones más importantes en el espacio románico respecto al latín es la creación de formas perifrásticas verbales para la expresión de la anterioridad (Coseriu 1977, Pöckl 2004, Gallardo Gil y Reina Bastardas 2007). Estas nuevas fórmulas verbales, que hoy en día funcionan en todas las lenguas romances, en mayor o menor medida, tienen un antecedente latino en las construcciones resultativas clásicas, como las que encontramos en los escritos de Cicerón: «In ea provincia pecunias magnas collocatas habent» [«en esa misma provincia tienen invertidas grandes fortunas»] (Camus 2008: 79).

Para pasar de este tipo de expresiones a lo que hoy entendemos por PPC tuvieron que sucederse una serie de cambios motivados por la evolución del latín al español o a otras lenguas romances, tales como: la gramaticalización de haber, que se acaba sustituyendo por tener para denotar la posesión, la identificación de la relación implícita entre el verbo y el participio, la delimitación de la conjugación del participio a masculino singular en el caso del español y la definición clara de usos y funciones tanto de auxiliar como de participio en la lengua.

Esta transformación se ha calificado de «invento románico», en palabras de Camus (2008), quien resalta el carácter excepcional de este período en la historia lingüística de la formación de las lenguas románicas, en el que se llega 
a conseguir combinar un auxiliar derivado de los verbos latinos habere y tenere con un participio léxico conjugado.

Esta idea del PPC como invención en romance nos parece particularmente sugerente y adecuada para resaltar tanto su valor innovador como la historia de cambios que ha ido experimentando en el caso del español, y que se extiende hasta la situación actual, en la que sigue todavía en proceso de reajuste y de evolución en gran parte de la geografía del mundo hispanohablante.

En la actualidad, el mapa del PPC con habere en la Europa románica se distribuye de la siguiente manera en español, catalán, francés, italiano, rumano, gallego y portugués (en estas dos últimas lenguas sustituido por el verbo tenere, forma preferida para indicar la posesión como lo era habere en latín):

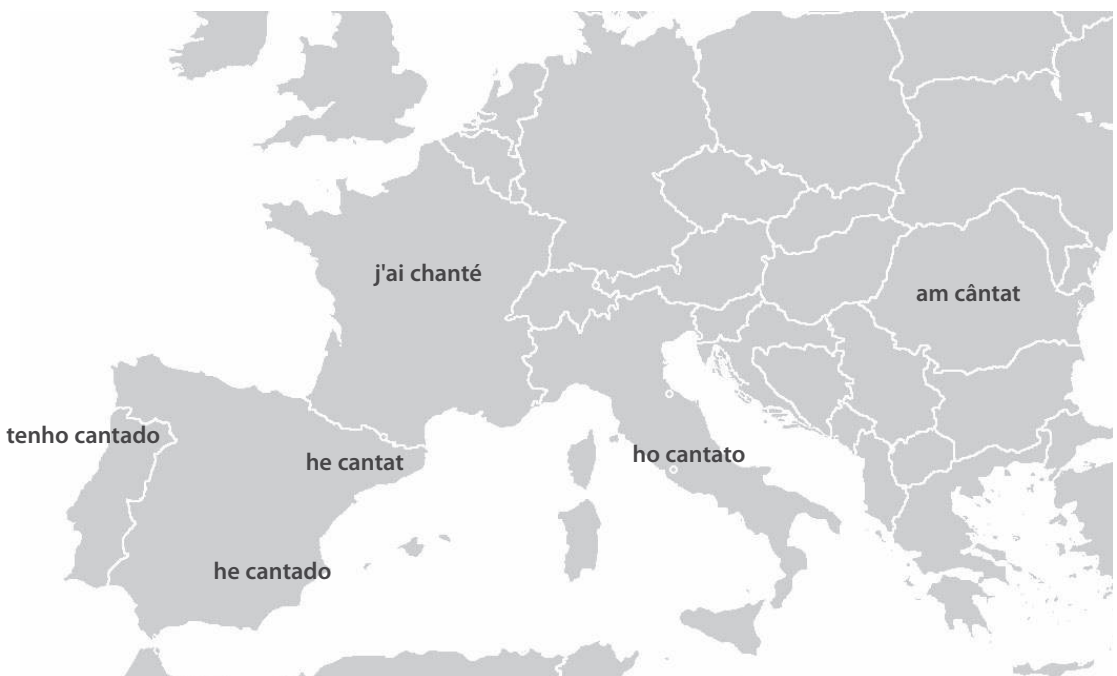

Imagen 1: Mapa de las formas del pasado compuesto en las principales lenguas románicas. Imagen modificada por el autor a partir de la imagen BlankEurope-BeforeKosovo.png $(<\mathrm{https} / /$ commons.wikimedia.org/wiki/Category:Blank_maps_of_Europe\#/media/File:BlankEuropeBeforeKosovo.png >), conlicencia CC-bySA3.0 (<https://creativecommons.org/licenses/by-sa/3.0/>).

Pero la gran innovación se produjo en el latín hablado al introducirse formas que podían indicar aspecto perfecto sin ambigüedades. Este proceso se inició primero entre los verbos transitivos, y consistía en la estructura habeo + participio. Dado que la actual posesión, expresada mediante habere, implicaba que la acción perteneciera a un período de tiempo todavía vigente, esta estructura estaba próxima a transmitir lo que transmite hoy el PPC, e hizo posible la distinción románica entre aspecto perfecto y perfectivo.

Los valores del perfecto compuesto en las lenguas románicas actuales se han alejado del valor estrictamente resultativo que tenía originalmente la perífrasis latina de la que proceden, y varían desde usos incipientes y limitados de aspecto perfecto a usos que incluyen también decididamente valores de aoristo. 
Tal como señalan Squartini y Bertinetto (2000: 416-417) y retoma Camus (2008: 96), el español europeo actual muestra una tendencia clara a extender sus valores a contextos aoristos, una «deriva», en palabras de estos autores, que tiende hacia usos propios del pasado remoto o perfectivo y que, en este trabajo, también enlazaremos con la situación del español de algunas regiones de América.

Se trata de un mismo fenómeno que se manifiesta en diferentes momentos y formas en distintas lenguas. Las perífrasis verbales que marcan resultados presentes de acciones pasadas están abocadas a gramaticalizarse en forma de PPC, es decir, como paradigmas que denotan evidencias pasadas que tengan relevancia presente.

Squartini y Bertinetto (2000), basándose en la propuesta clásica de Harris (1982), desarrollan la llamada teoría del aorist drift o deriva de aoristo, proceso de evolución de los usos y valores del PPC en cuatro etapas en el espacio románico, que se recoge a continuación:

Estadio 1. Se usa para la expresión de estados presentes que resultan de acciones pasadas, con valor puramente resultativo. No se utiliza para describir las propias acciones pasadas, ni siquiera las recientes. Es lo que ocurría en latín vulgar. No hay lenguas romances en la actualidad que tengan PPC con este valor.

Estadio 2. Aparece en contextos marcados aspectualmente como durativos o iterativos. Se utiliza en situaciones que han dado comienzo en el pasado y continúan en el momento del habla, como ocurre hoy en día en portugués, gallego, siciliano y en la mayoría de las variedades del español, tanto en Europa como en América.

Estadio 3. Describe acciones pasadas recientes o conectadas en el momento del habla. Es el caso canónico del español normativo más tradicional, que coincide con los usos típicos del español peninsular, así como del occitano y catalán.

Estadio 4. Describe acciones pasadas no necesariamente recientes. A su vez, el pretérito perfecto simple suele quedar restringido a los registros formales. Esto ocurre en francés, italiano, rumano, retorrománico y sardo.

En este trabajo, yendo más lejos con esta propuesta, que ha sido ampliamente refrendada por la literatura del ámbito de la lingüística románica de los últimos años, seremos testigos de algo excepcional: ver cómo la tendencia del español actual, tanto en la península ibérica como en Hispanoamérica, es la de ir derivando hacia el estadio número cuatro de aoristización, tal como hicieron en su momento el francés o el italiano. Estamos ante un proceso de gramaticalización, una tendencia innovadora, dinámica y constante que, como la definiría Company (2002: 43), nunca concluye y que se centra en la reestructuración y organización de la gramática. Esta cristalización de los usos de la lengua, que puede perder o ver transformado su significado específico como 
consecuencia de una alta frecuencia de uso (Moreno Fernández 2012: 131), no tiene que llegar a un final necesariamente, ni implicar un cambio externo de gran calado, pues dos valores distintos producto de un proceso de gramaticalización pueden convivir por siglos bajo un mismo exponente formal.

Esta podría ser la situación de excepción en la que se encuentra la posición transitoria, de «vaguedad temporal» (Henderson 2010: 61), y de cambio de significado entre el tercer y cuarto estadio de aoristización, del pretérito perfecto en español, actualmente a medio camino entre ambas fases.

\section{Tradición, norma y excepción}

A pesar de su extraordinaria historia, si atendemos a los valores normativos asignados tradicionalmente al pretérito perfecto, podemos considerar que se trata del único tiempo compuesto anclado en el momento del habla y que, además, se interpreta en gran parte de los casos temporalmente como un presente. El PPC expresa además la persistencia actual de hechos pretéritos, al evaluar la situación desde el presente, pero a la vez afirmar algo acerca de un período anterior.

Estos valores, que sin duda se encuentran muy asentados en el español europeo, especialmente en la zona central y meridional de la península ibérica, muestran una tendencia al cambio lingüístico al adquirir nuevos matices en otras áreas del mundo hispánico. Y es que, tal como señala la Real Academia Española (RAE) y la Asociación de Academias de la Lengua Española (ASALE) en su última Gramática: «Puede, pues, afirmarse que el PPC es la forma verbal cuyos usos muestran mayor variación geográfica en el español de hoy» (2009: 1721).

La variación a la que se refieren implica que, en algunas regiones, la oposición perfecto simple/perfecto compuesto sea más aspectual que temporal, y que en otras áreas la oposición se neutralice en favor de la forma simple, tal como ocurre en el noroeste de España, las islas Canarias, el Caribe o la América austral. Nuevos usos, más recientemente descritos por los especialistas, hablan también de neutralizaciones a la inversa, en las que la forma resultante y dominante sería la compuesta, tal como ocurre en el País Vasco y el centro-sur de la península ibérica (Serrano 1994, Schwenter 1994a, Kempas 2008, Azpiazu 2015) o en los países de la región andina (Klee y Ocampo 1996, Kempas 2006, Jara 2011, Howe 2013 y Seco 2015)3.

Según la tradición del español y la norma de la mayoría de las lenguas que presentan un paradigma verbal con pretéritos de indicativo simples y compuestos, ambos tiempos se combinan con expresiones temporales

3 Muchos de estos usos han sido propiciados o extendidos desde regiones bilingües y en contextos propios de zonas de lenguas en contacto, como ha ocurrido en el País Vasco gracias a la influencia del euskera o en la América andina por la reestructuración del sistema verbal en español llevada a cabo por los hablantes de quechua. 
diferentes. El perfecto compuesto es compatible con expresiones temporales que denotan un tiempo que se incluye en el momento del habla o está incluido en un intervalo que abarca también simultaneidad. El PPC puede emplearse para expresar simultaneidad con respecto a otro perfecto compuesto, pero no con respecto a un tiempo simple. Para Carrasco (2008: 26), estos y otros datos son prueba de la distinta indicación temporal de anterioridad que realizan ambos pretéritos, lo que nos haría ver la necesidad de mantener estructuras temporales diferenciadas en la lengua. Un proceso que se respeta a nivel normativo, pero que tiende a converger o neutralizarse en favor de la forma simple o compuesta según los usos regionales.

La RAE y la ASALE, en su Nueva gramática (2009: 1854), hablan a este respecto de una doble agrupación del PPC con tiempos de ambas esferas, presente y pasado. De hecho, van más allá, considerando el doble acceso interpretativo del PPC no solo en contextos de actualidad y anterioridad, sino también en contextos de posterioridad.

Parece evidente que la indeterminación temporal -ese "puzle» al que se refiere Klein (1992)-, es clave para la proliferación de usos y contextos del PPC que, quizás, estén conectados con fenómenos pragmáticos que indiquen una posible relevancia o énfasis en la enunciación.

Pero no será esta la primera vez que se hable sobre el PPC en una gramática, ni mucho menos. Antonio de Nebrija, en 1492, trata el tema que nos ocupa al ejemplificar la conjugación de los tiempos pasados: «En el mesmo tiempo por rodeo, e amado, as amado, a amado, avemos amado, avéis amado, an amado» (según la edición de Anguita 2005: 218). Nebrija utiliza la expresión de tiempo «por rodeo» para referirse a todos los pasados compuestos de la conjugación. En el caso concreto del PPC, lo asocia al pasado acabado, considerándolo prácticamente un sinónimo del pretérito anterior y otra manera equivalente de conjugar el pretérito perfecto simple.

El «deslinde» (Quijada 2014) entre las formas canté y he cantado aparece tratado por primera vez de manera explícita en el siglo xvi en la Vtil y Breue Institvtion:

Los mesmos modos y tiempos tiene la lengua Española, que los latinos: excepto que los Hespañoles tienen dos praetéritos. El primero es conforme al Aoristo delos Griegos: porque significa lo passado, pero sin determinar tiempo: Como yo amé, yo salté. El segundo significa el tiempo praetérito más cerca passado, y determinando tiempo: Como yo he amado, yo he saltado, del qual vsamos quando oy, ô ayer, ô poco antes, auemos amado, ô saltado. (Anónimo 1555: 41)

Apreciamos en este fragmento las referencias exactas a la diferencia aspectual de ambas formas, la simple y la compuesta, así como su combinación con posibles marcadores temporales y contextos vigentes todavía en los usos actuales de estos tiempos.

Siglos después, la RAE zanjará el tema recurrente de la alternancia de los pretéritos y sus posibles excepciones con la siguiente advertencia que achaca a las costumbres de los escritores afrancesados que imitan la lengua del país vecino, 
cuya tendencia en favor del PPC o passé composé ya estaba consolidada en esa época: «Se advierte que algunos escritores del día emplean sin discernimiento el pretérito compuesto, imitando a los franceses, cuyo idioma no admite el simple sino en muy contadas ocasiones» (1854: 49-50).

Hoy en día, el concepto de lo normativo o la norma es una abstracción que reúne hechos característicos de una lengua determinada correspondientes a un mismo espacio funcional. Es un concepto en el que se agrupa lo general, pero que no se limita a lo absolutamente constante y uniforme. Parece que hemos llegado a un momento de madurez en los procesos de normativización y estandarización de ámbito panhispánico, en el que las instituciones responsables de la descripción de la lengua han decidido unirse y consensuar diferentes grados de normatividad que configuran una suerte de subsistemas con sus propias leyes y excepciones desprendidos del sistema más general (Bravo García 2008). Por eso, podría llegar a pensarse en ocasiones que no existe una norma hispánica en un sentido singular, sino un conjunto de diferentes normas que confluyen o se cruzan parcialmente en distintas coordenadas y que conforman de una manera pluricéntrica y contrapunteada la lengua española, tal como la entendemos hoy sus hablantes (Lebsanft, Mihatsch y Polzin-Haumann 2012). En el prólogo de la Nueva gramática de la lengua española ${ }^{4}$ se aborda el asunto de la norma del español en los siguientes términos:

La norma hoy tiene carácter policéntrico. La muy notable cohesión lingüística del español es compatible con el hecho de que la valoración social de algunas lenguas construcciones pueda no coincidir en áreas lingüísticas diferentes. No es posible presentar el español de un país o de una comunidad como modelo panhispánico de lengua (RAE y ASALE 2009: XLII).

Estamos, sin duda, ante toda una declaración de principios institucional que asocia por primera vez, y de manera unívoca, la dimensión dialectal a la descripción de la gramática española y al reconocimiento expreso a sus posibles variaciones, y cómo estas pueden afectar a las normas regionales o nacionales en el mundo hispanohablante, como sabemos que ocurre con el caso particular del PPC.

\section{Usos y valores excepcionales}

Queda claro que el valor del PPC más conocido es el de anterioridad con respecto al punto de referencia situado en el presente. Este valor, que además coincide plenamente con su empleo normativo, descrito en todos los materiales didácticos para la enseñanza de español como lengua extranjera, que parecen seguir, en gran medida, la representación que del pretérito perfecto se realizaba

4 La Nueva gramática de la lengua española es la primera gramática académica desde 1931, si no consideramos con el mismo grado de oficialidad con respecto a la norma ni al Esbozo de 1973 ni a la Gramática descriptiva de 1999, que, de hecho, son gramáticas que la Real Academia encarga a autores particulares. 
en la Gramática académica de 1931, dista mucho, sin embargo, de utilizarse de manera extendida y uniforme por todo el mundo hispánico (Soler Montes 2017). Lo encontramos habitualmente en las hablas del español europeo con limitaciones en la región noroeste de la península ibérica y las islas Canarias, pero, tal como se explicará más adelante en este apartado, registra tendencias de empleo diferentes en el resto de áreas lingüísticas del español, que pueden dotarlo de nuevas representaciones aspectuales con fuerte carácter evidencial, o descartarlo por la forma simple.

La Gramática de la RAE y la ASALE (2009) contiene una de las más completas y actuales descripciones de los múltiples usos que los hablantes de español confieren al PPC. Estos son los principales valores que se presentan:

Valor de antepresente. El PPC se utiliza para referirse a situaciones previas al momento de la enunciación, pero desde la perspectiva actual que le confiere el habla. Este es valor canónico, claro, reconocido y compartido por todos los hispanohablantes en ejemplos como:

(1) Claro, hasta ahora pues he estado estudiando, no me he planteado el trabajar. (CHCS: 32$)^{5}$

Valor perfectivo y de aoristo. Se trata del uso del PPC en contextos propios del perfecto simple con referencias temporales de pasado remoto. Este uso está presente en varias lenguas romances en las que la forma compuesta ha ido ganando terreno a los valores propios de la forma simple, como ocurre en francés o en italiano. Los autores de la teoría sobre la "deriva de aoristo», Squartini y Bertinetto (2000: 421), apuntan que «if the aoristic drift carries on in the future as it has done so far, there will eventually be a point when Spanish and French coincide» ["si la deriva de aoristo continúa desarrollándose en el futuro como lo ha hecho hasta ahora, llegará un momento en el que coincidan finalmente el español y el francés»].

(2) Entonces de ahí, volvimos a Ginebra, donde partimos con un tour hacia Grecia. Atravesamos toda Italia, toda Italia casi hemos conocido. (CHCL: 119)

(3) Como éramos una familia de piña y de grupo, y además tenía un montón de primos, y los veranos nos juntábamos mucho con gente joven, y yo era estudiosita, entonces teníamos en casa un ambiente de estudio bueno, pero teníamos un ambiente de juerga entre hermanos. Nos hemos divertido muchísimo. (CHCS: 182)

5 Para dotar de mayor verosimilitud a la contextualización de la investigación, la gran mayoría de ejemplos que se han utilizado en esta sección provienen de la lectura y el análisis propio de apariciones de formas del pretérito perfecto compuesto en dos corpus de habla culta incluidos en el marco de la Comisión de Lingüística y Dialectología Iberoamericanas del Proyecto Interamericano de Lingüística (PILEI), un corpus europeo y otro americano. Se trata del Corpus del habla culta de Salamanca (CHCS) publicado por Fernández Juncal en 2005 y del Corpus del habla culta de Lima (CHCL) publicado por Caravedo en 1989. 
Valor existencial. A pesar de que esta característica se asocia al presente, se puede reconocer también en algunos usos y contextos del PPC (RAE y ASALE 2009: 1723), que entrarían en consonancia con esta expansión de uso y frecuencia que pretendemos mostrar en este trabajo. Así, en casos como:

(4) Me presenté a la oposición, la saqué y he estado catorce años de profesora titular. (CHCS: 159)

Se infiere que la informante es ya «profesora titular». No llegaríamos a la misma nitidez ni a la misma conclusión si esta persona se hubiera expresado de la siguiente manera:

(5) Me presenté a la oposición, la saqué y estuve catorce años de profesora titular.

Ocurre lo mismo en este ejemplo:

(6) [Mi papá] se ha retirado simplemente porque ya estuvo mucho tiempo en Piura y alejado de la familia. (CHCL: 86)

En este caso entendemos de manera más explícita que el padre del hablante sigue vivo que si se hubiera utilizado se retiró. En nuestra opinión, este tipo de interpretaciones del PPC confiere una sensación de apertura y vigencia temporal al discurso en un ámbito del pasado que activa implicaciones pragmáticas de relevancia o énfasis. Sin embargo, en RAE y ASALE (2009) se restringe este uso existencial a oraciones atributivas en las que se describen propiedades de sujetos de actualidad permanente o fama, pero que ya no viven:

(7) Andrés Bello ha sido el mejor gramático de la lengua española. (2009: 1723)

Este tipo de oraciones, muy comunes en el lenguaje periodístico, en discursos laudatorios o ensayos históricos, se encuentra en contraste con casos poco habituales en español normativo como el siguiente:

(8) Tuvimos la suerte de tener a mi abuelita en la casa. Y fue ella prácticamente la que nos ha criado. (CHCL: 125)

El hablante, en este ejemplo, se refiere a un familiar ya fallecido, por lo que el uso del PPC no resulta natural y parece de difícil interpretación en ausencia de complementos temporales concretos. Estos usos se mencionan como propios del español andino (RAE y ASALE 2009: 1723), aunque no se aporta ningún ejemplo auténtico proveniente del español de España como los que sí se están utilizando en el presente trabajo.

Valor prospectivo o de planificación. Valor caracterizado por aludir a hechos futuros a través del apoyo de complementos temporales que sitúan la acción en un momento posterior a la enunciación.

(9) Mañana a estas horas seguro que ya hemos terminado el informe. (2009: 1724)

Si bien no se hacen referencias a la distribución geográfica de este valor, sí especifica que este tipo de usos se encuentra en América, pero con la forma simple del pretérito perfecto, tanto en México como en Centroamérica, Río de la Plata y Perú. 
(10) Para el miércoles próximo ya lo mandé. (2009: 1724)

Valor de interpretación habitual o iterativa. Valor muy relacionado con el uso habitual o cíclico de presente de indicativo (RAE y ASALE 2009: 1711), que alude a situaciones repetidas como las referidas a la rutina diaria, pero que con el PPC suele estar acompañado de cuantificadores universales del tipo cada vez o siempre.

(11) Creo que he sido una niña tremendamente feliz, muy feliz porque... No sé, siempre me he visto muy arropada. (CHCS: 33)

(12) Ahora yo siempre, después que he regresado a Lima, siempre he viajado, como estudiante, ya sea tirando dedo. O este, en ómnibus. (CHCL: 29)

Valor de experiencia o experiencial. Valor que incide en la mención de una situación ya experimentada al menos una vez y que se describe en un período temporal pasado, en el que se produce primero, y se narra o se retoma en el momento de la enunciación de manera arbitraria. Bybee, Perkins y Pagliuca (1994: 61) constatan que este valor carece de localizadores temporales concretos y que, en general, describe acciones que ocurren alguna vez en la vida.

(13) Y esos libros que hay ahí los he revuelto cien mil veces. (CHCS: 275)

(14) He ido varias veces sí, he ido varias veces. Últimamente... o sea esto el año mil novecientos sesenta y nueve, setenta, he ido en bote de regata. (CHCL: 64)

Valor continuo o universal. Está relacionado con una acción o evento que se extiende al momento presente dando a entender, en la mayoría de los casos, que se puede continuar en un futuro. Estos perfectos aparecen con complementos que miden la duración de la situación que se describe y que no necesariamente concluye en el momento del habla.

(15) No se me ha perdido nada en este pueblo. Nada. Ni está mi marido ni nada. Claro, he, he llorado durante dos años. (CHCS: 237)

(16) Durante mi época de estudiante he hecho trabajos de investigación de campo. (CHCL: 31)

Valor de sucesos recientes o pasado inmediato. En estos casos se muestra una cercanía temporal al presente que, en ocasiones, producto de la novedad o relevancia de lo dicho para el contexto, puede relacionarse con una noticia informativa o un titular. De ahí su nombre en inglés, hot news. Se trata de un valor que encontramos en España y en la región andina. Al utilizar el perfecto en estos casos, hay que tener en cuenta que el período temporal al que corresponde la acción no puede haber terminado en el momento de la enunciación (el día de hoy, la semana, el mes actual, el año).

(17) $\mathrm{Y}$ este año hemos ido. Entonces este año ya se ha animado mi marido. (CHCS: 258)

Las noticias periodísticas son eventos que se suelen difundir en un breve transcurso de tiempo desde que ocurren. El valor de perfecto de noticias recientes o hot news hace referencia al momento de la enunciación en el 
que se informa de hechos de interés general. Schwenter (1994b: 1001) se centra en describir esta relación especial de la primera mención de lo transcurrido con el momento del habla al entender «hot news closer to the normal functions of perfective, which present bounded (past) situations for their own sake, and not in relations to speech time» [«las noticias recientes más próximas a las funciones propias del aspecto perfectivo, que presentan situaciones (pasadas) limitadas por sí mismas, y no relacionadas con el momento del habla»].

Valor hodierno ${ }^{6} \mathbf{u}$ hodiernal. Este tipo de pretéritos, muy relacionados con los usos que se han descrito al hablar del valor de pasado inmediato, van acompañados de adjuntos temporales que enmarcan la acción dentro del día en el que se está hablando. Es interesante pensar en las diferencias que se señalan en RAE y ASALE (2009: 1730) con respecto a este valor en casos como:

(18) Se ha levantado a las cinco de la mañana.

(19) Se levantó a las cinco de la mañana.

En español europeo, mientras que en el primer ejemplo se hace referencia al día de la enunciación, en el segundo caso podemos estar refiriéndonos a una acción no necesariamente vinculada con el hoy del hablante, sino con cualquier otro día. Según la llamada «regla de las 24 horas» (MartínezAtienza 2008: 216), el PPC puede estar modificado por un complemento circunstancial solo si este denota un intervalo que forma parte del día de la enunciación, hoy. Este presupuesto solo resultaría válido si se tiene en cuenta que no implica que el evento haya de tener lugar en ese día. Puede haber comenzado mucho antes del momento del habla siempre que una parte, al menos, incluya al día de hoy. En algunas regiones de la América andina sí se podría alargar el ámbito de acción del pretérito perfecto para retrotraerlo a contextos mucho más remotos como en:

(20) En Uruguay he estado en el año cincuenta y ocho. (CHCL: 167)

Valor narrativo. En las variedades lingüísticas del español en las que encontramos una mayor tendencia hacia el uso del PPC, la europea y la andina, podemos encontrar también este valor caracterizado por dar «mayor viveza» (RAE y ASALE 2009: 1731) al discurso en el que se enumeran o yuxtaponen distintas acciones, cercanas al momento del habla en el español europeo o extrapoladas desde el pasado remoto en el caso del español andino, pero siempre buscando provocar algún efecto de tipo enfático o evidencial en el interlocutor, ya sea estilístico o psicológico.

(21) Me ha costado como a todas. Lo que pasa que, como todas, me he creído que era muy lista y lo sabía hacer todo estupendamente. Tonterías. Claro. Has tenido una familia con un marido, unos hijos. Has criado, has descriado, has acudido a tus padres. (CHCS: 188)

6 Del latín hodiernus 'del día de hoy', derivado de hodǐe 'hoy'. 
(22) Y en segundo viaje, llegué a Boston, y de Boston me he ido hacia Chicago y de allí he regresado a Michigan, ¿no?, toda esa zona... Wisconsin, he cruzado el lago Michigan también, he ido a Minnesota. (CHCL: 68)

La diferencia que se extrae del uso del PPC en estos contextos puede provocar contrastes de interpretación, pero nunca de gramaticalidad. Todo radica en la capacidad de entender estas acciones como relevantes o pertinentes y, por lo tanto, conectadas con el momento del habla.

Valor resultativo. Se trata de aquellas formas de PPC que se refieren a acciones pasadas que presentan una incidencia directa y clara sobre el estado actual que, además, se convertirá en un resultado de lo expresado con anterioridad. El PPC transmite una idea de perdurabilidad en el momento de la enunciación mucho más sólida, acentúa la novedad que produce la transmisión de la información reciente. Esta construcción es común en todo el mundo hispánico, se utiliza tanto en España como en América, donde ha sido ampliamente recogida y estudiada en varias ocasiones (Lope Blanch 1986, Alvar 1996, Moreno de Alba 2003, Henderson 2010).

(23) Y a mí lo que más me ha valido es el enfoque, el enfoque y la pasión. (CHCS: 175)

(24) A raíz de que nos hemos casado parece que el no, el dejarnos de vernos ha hecho pues, este, reactivar esto. (CHCL: 85)

Vemos, pues, que estos valores se concentran en torno a distintos recorridos respecto al momento en que ocurre la acción verbal y el momento del habla, así como en distintas áreas geográficas de uso, que se podrían esquematizar en la siguiente tabla:

Tabla 1: Síntesis de las tres representaciones aspectuales más representativas de los valores del PPC y su distribución por regiones en el mundo hispánico.

\begin{tabular}{|c|c|c|}
\hline Pasado reciente & Pasado actual & Pasado lejano \\
\hline Peninsular & Panhispánico & Peninsular y andino \\
\hline $\begin{array}{l}\text { Se emplea para aludir a un } \\
\text { tiempo pasado, anterior al } \\
\text { momento actual. La mayor } \\
\text { o menor distancia cronoló- } \\
\text { gica entre la acción expre- } \\
\text { sada y el momento de la en- } \\
\text { unciación no es lo decisivo. }\end{array}$ & $\begin{array}{l}\text { Pasado cuya acción, aun } \\
\text { perteneciendo al pasado, } \\
\text { continúa en el presente y } \\
\text { se presenta como no termi- } \\
\text { nada, es decir, como una ac- } \\
\text { ción o estado cuyos efectos } \\
\text { o resultados perduran en el } \\
\text { momento de la enunciación. }\end{array}$ & $\begin{array}{l}\text { Pone de relevancia he- } \\
\text { chos transcurridos en un } \\
\text { momento temporalmente } \\
\text { distanciado del tiempo de } \\
\text { la enunciación. Es eviden- } \\
\text { cial, se utiliza cuando el } \\
\text { hablante quiere dar énfasis o } \\
\text { relevancia a una acción que } \\
\text { concluyó en el pasado. }\end{array}$ \\
\hline
\end{tabular}

\section{Conclusión}

La oposición constituida por el pretérito perfecto simple y el perfecto compuesto de indicativo, la delimitación de sus valores comunes y sus rasgos 
distinguidores conforman uno de los aspectos que presenta mayor variación gramatical en el español actual, frente a lo sucedido en otras lenguas romances, que terminaron claudicando ante la elección de solo una de las dos formas de pasado, con el fin de simplificar la oposición que parece ser compleja o innecesaria para el uso que los hablantes le dan en sus respectivas lenguas. En español, aunque la oposición canté/he cantado se mantiene vigente, forma parte incuestionable de la norma, se enseña y se aprende, parece tender también a simplificarse en según qué zonas del mundo hispánico. En algunas de ellas hay una clara predilección, o un uso casi exclusivo, de la forma simple, mientras que en otras se tiende a privilegiar más el uso de la forma compuesta en convivencia, aún, con la forma simple.

Varios años después de la aparición de la última gramática académica (RAE y ASALE 2009) todavía se sigue pensando que el uso del PPC es parcial o reducido dentro del contexto general de la lengua española, y que está asociado casi en exclusiva al español de España o al de «algunos peruanos y bolivianos» (Potowski y Shin 2018: 96). Este tipo de creencias, tildadas con humor de «mito peninsular» por su persistencia y generalización en ámbitos como el de la enseñanza de español como lengua extranjera (Llopis-García, Real Espinosa, Ruiz Campillo 2012: 74), parte de una verdad a medias, promovida por la necesidad pedagógica de simplificación de la lengua, así como de la tendencia a dividir la lengua española en dos mitades (español de España y español de América). Se ampara además en el desconocimiento general de la riqueza lingüística y dialectal de la lengua española, y en su interconexión transnacional, que se ha ido tejiendo a través de siglos de historia cultural común. Ya ha quedado demostrado aquí cómo las tendencias que asocian el pretérito perfecto simple al español americano y el perfecto compuesto al europeo no representan bien una realidad excepcional, plagada a su vez de múltiples excepciones, por muy tentador o rentable que pueda ser dividirlo así a efectos pedagógicos, especialmente en el contexto de la enseñanza de la lengua (Soler Montes 2017, Comajoan-Colomé y Pérez Saldanya 2018).

Y es que, tal como anticipó López Morales hace más de dos décadas hablando de los principales rasgos del español de América que se deberían investigar mejor: «uno de los casos de mayor significación son los usos de formas verbales como canté/he cantado, que prometen ser de mucho rendimiento» (1996: 25) y que, de hecho, lo han sido.

\section{Bibliografía}

Alvar Ezquerra M. (dir.), 1996, Manual de dialectología hispánica. El español de América, Barcelona, Ariel.

Anguita J. A. (ed.), 2005, Una aproximación a la gramática de Nebrija, Sevilla, Alfar. 
Anónimo, 1555, Útil y breve institución para aprender los principios y fundamentos de la lengua española, Lovaina. Ed. Facs. y estudio introductorio de A. Roldán, 1977, Madrid, CSIC.

Azpiazu S., 2015, «La variación Antepresente/Pretérito en dos áreas del español peninsular», Verba, no 42, p. 269-292.

Bello A., 1847, Gramática de la lengua castellana destinada al uso de los americanos, Santiago de Chile, Imprenta del Progreso.

Bravo García E., 2008, El español internacional. Conceptos, contextos y aplicaciones, Madrid, Arco Libros.

Bybee J., Perkins R. y Pagliuca W., 1994, The Evolution of Grammar: Tense, Aspect, and Modality in the Languages of the World, Chicago, University Press.

Camus Bergareche B., 2008, «El perfecto compuesto (y otros tiempos compuestos) en las lenguas románicas: formas y valores», in Carrasco Gutiérrez A. (ed.), Tiempos compuestos y formas verbales complejas, Madrid/Fráncfort, Iberoamericana Vervuert, p. 65-102.

Caravedo R., 1989, El español de Lima. Materiales para el estudio del habla culta, Lima, Pontificia Universidad Católica del Perú.

Carrasco Gutiérrez A., 2008, «Los tiempos compuestos del español: formación, interpretación y sintaxis», in Carrasco Gutiérrez A. (ed.), Tiempos compuestos y formas verbales complejas, Madrid/Fráncfort, Iberoamericana Vervuert, p. 13-64.

Cartagena N., 1999, "Los tiempos compuestos», in Bosque I. y Demonte V. (dirs.), Gramática descriptiva de la lengua española, Madrid, Real Academia Española/Espasa, p. 2935-2975.

Comajoan-Colomé L. y Pérez Saldanya M., 2018, Los tiempos verbales del español. Descripción del sistema y su adquisición en segundas lenguas, Barcelona, Octaedro.

Company Company C., 2002, «Gramaticalización y dialectología comparada. Una isoglosa sintáctico-semántica del español», Cuadernos de Filología Hispánica, n²0, p. 39-71.

Comrie B., 1976, Aspect, Cambridge, University Press.

Coseriu E., 1977, Estudios de lingüística románica, Madrid, Gredos.

Fernández Juncal C., 2005, Corpus del habla culta de Salamanca, Burgos, Fundación Instituto Castellano y Leonés de la Lengua.

Gallardo Gil J. E. y Reina Bastardas M., 2007, Manual de lingüística románica, Barcelona, Ariel.

Gutiérrez Araus M. L., 1997, Formas temporales del pasado de indicativo, Madrid, Arco Libros.

Harris M., 1982, "The past simple and the present perfect in Romance», in Vincent N. y Harris M. (eds.), Studies in the Romance Verb, Londres, Croom Helm, p. 42-70. 
Henderson C., 2010, El pretérito perfecto compuesto del español de Chile, Paraguay y Uruguay. Aspectos semánticos y discursivos, Tesis doctoral, Universidad de Estocolmo.

Howe C., 2013, The Spanish Perfects: Pathways of Emergent Meaning, Basingstoke, Palgrave Macmillan.

Jara M., 2011, «Funciones discursivas y gramaticalización del pretérito perfecto compuesto en el español de Lima», Spanish in Context, no 8: 1, p. 95-118.

Kempas I., 2006, Estudio sobre el uso del pretérito perfecto prehodiernal en el español peninsular y en comparación con la variedad del español argentino hablada en Santiago del Estero, Tesis doctoral, Universidad de Helsinki.

Kempas I., 2008, «El pretérito perfecto compuesto y los contextos prehodiernales», in Carrasco Gutiérrez A. (ed.), Tiempos compuestos y formas verbales complejas, Madrid/Fráncfort, Iberoamericana Vervuert, p. 231-273.

Klee C. y Ocampo A., 1996, "The Spanish of the Peruvian Andes: The influence of Quechua on Spanish language structure», in Roca A. y Jensen J. (eds.), Spanish in Contact. Issues in Bilingualism, Somerville, Cascadilla Press.

Klein W., 1992, «The present perfect puzzle», Language, no 68, p. 525-52.

Lebsanft F., Mihatsch W. y Polzon-Haumann C. (eds.), 2012, El español, ¿desde las variedades a la lengua pluricéntrica?, Madrid/Frankfurt, Iberoamericana Vervuert.

Llopis-García R., Real Espinosa J. M. y Ruiz Campillo J. P., 2012, Qué gramática enseñar, qué gramática aprender, Madrid, Edinumen.

Lope Blanch J., 1986, El estudio del español hablado culto. La historia de un proyecto, México, Universidad Nacional Autónoma de México.

López Morales H., 1996, «Rasgos generales», Alvar M. (dir.), Manual de dialectología hispánica. El español de América, Barcelona, Ariel, p. 19-27.

Martínez-Atienza M., 2008, «Dos formas de oposición en el ámbito románico entre el pretérito perfecto compuesto y el pretérito perfecto simple», in Carrasco Gutiérrez A. (ed.), Tiempos compuestos y formas verbales complejas, Madrid/Fráncfort, Iberoamericana Vervuert, p. 203-230.

Moreno de Alba J., 2003, Estudios sobre los tiempos verbales, México, D.F., Universidad Nacional Autónoma de México.

Moreno Fernández F., 2012, Sociolingüística cognitiva. Proposiciones, escolios y debates, Madrid/Fráncfort, Iberoamericana Vervuert.

Pöckl W., 2004, Introducción a la lingüística románica, Madrid, Gredos.

Potowski K. y Shin N., 2018, Gramática española. Variación social, Londres, Routledge.

Quijada Van den Berghe C., 2014, «El deslinde PPS y PPC en la tradición gramatical española del siglo xıx: cuestiones teóricas, descriptivas y normativas», in San Vicente F., Hériz A. L. y Pérez Vázquez M. E. (eds.), Perfiles para la historia y crítica de la gramática del español en Italia: siglos XIX y XX Confluencia y cruces de tradiciones gramaticográficas, Bolonia, University Press: 93-108. 
Real Academia Española, 1854, Gramática de la lengua castellana. Madrid, Imprenta Nacional.

Real Academia Española, 1931, Gramática de la lengua española, Madrid, Espasa Calpe.

Real Academia Española y Asociación de Academias de la Lengua Española, 2009, Nueva gramática de la lengua española, Madrid, Espasa.

Rojo G., 1974, «La temporalidad verbal en español», Verba. Anuario galego de filoloxia, $\mathrm{n}^{\circ} 1, \mathrm{p} .68-149$.

Rona J. P., 1973, «Tiempo y aspecto: Análisis binario de la conjugación española», Anuario de Letras, $\mathrm{n}^{\circ} \mathrm{XI}$, p. 211-223.

Schwenter S. A., 1994a, "The grammaticalization of an anterior in progress: Evidence from a peninsular Spanish dialect», Studies in Language, $\mathrm{n}^{\circ} 18$, p. 71-111.

Schwenter S. A., 1994b, "Hot news and the grammaticalization of perfects», Linguistics, no 32 , p. 995-1028.

Seco M. A., 2015, «El pasado perifrástico en variedades del español americano: Panorama de los estudios recientes», Signo y Seña, no 28, p. 211-235.

Serrano M. J., 1994, «Del pretérito indefinido al pretérito perfecto: un caso de cambio y gramaticalización en el español de Canarias y Madrid», Lingüística Española Actual, no 16/1, p. 21-57.

Soler Montes C., 2017, «La variación gramatical y el aprendizaje de los tiempos verbales del pasado en el contexto del español como lengua extranjera», in Ainciburu C. (ed.), La adquisición del sistema verbal del español. Datos empíricos del proceso de aprendizaje del español como lengua extranjera, Fráncfort, Peter Lang, p. 235-266.

Squartini M. y Bertinetto P. M., 2000, «The simple and compound past in Romance languages», in Dahl O. (ed.), Tense and Aspect in the Languages of Europe, Berlín, Walter de Gruyter, p. 403-439.

Weinrich H., 1964, Estructura y función de los tiempos en el lenguaje, Madrid, Gredos. 